\title{
LAS LOCALIDADES INTERMEDIAS Y LOS SISTEMAS URBANOS-REGIONALES EN ARGENTINA
}

\author{
Mariana Schweitzer \\ Santiago Petrocelli \\ Marisa Scardino \\ Universidad de Buenos Aires. FADU-CIHaM \\ Directora: Mariana Schweitzer \\ marianaschweitzer@conicet.gov.ar
}

\section{RESUMEN}

El análisis de un sistema regional permite evaluar el funcionamiento de las relaciones entre asentamientos en clave de su oferta de servicios y equipamientos para la población y para el desarrollo de las actividades productivas. Las localidades intermedias, por la función que desempeñan en su entorno, son centros de interacción social, económica y cultural; ofrecen empleos, servicios e infraestructura colectiva a la población urbana y rural, y su rol es determinante en áreas alejadas de los grandes centros urbanos. El presente trabajo retoma el debate de las localidades intermedias, sus funciones y dinámicas, con el fin de generar aportes para la toma de decisiones en materia de ordenamiento del territorio para lograr mayor equidad territorial. El abordaje metodológico es multidimensional y multiescalar, articulando técnicas cuantitativas y espaciales en base al análisis cartográfico y estadístico. Se consideran dos casos de estudio: Pergamino y Ushuaia, en Argentina.

\section{Palabras clave: TERRITORIO; SISTEMA REGIONAL-URBANO; CIUDADES INTERMEDIAS}

\begin{abstract}
The analysis of a regional system allows to evaluate the functioning of the relations between cities in terms of their offer of services and equipment for the population and for the development of productive activities. The intermediate localities, by the function that they perform in their environment, are centers of social, economic and cultural interaction; they offer jobs, services and collective infrastructure to the urban and rural population, and their role is decisive in areas far from the large urban centers. The present work takes up the conversation of the intermediate localities, their functions and dynamics, with the purpose of generating contributions for the decision making about territorial ordering to achieve a better territorial equity. The methodological approach is multidimensional and multiscalar, articulating quantitative and spatial techniques based on cartographic and statistical analysis. Two cases of study are considered: Pergamino and Ushuaia, both in Argentina.
\end{abstract}

Key words: TERRITORY; REGIONAL-URBAN SYSTEM; INTERMEDIATE CITIZENS 


\section{INTRODUCCIÓN AL TEMA}

El análisis de un sistema regional permite evaluar el funcionamiento de las relaciones entre asentamientos humanos de un territorio en relación a la oferta de servicios y equipamientos para la población y para el desarrollo de las actividades productivas. Las localidades intermedias, por la función que desempeñan en su entorno, son centros de interacción social, económica y cultural; ofrecen empleos, servicios e infraestructura colectiva a la población urbana y regional. Su rol es determinante en áreas alejadas de los grandes centros urbanos, con efectos dinamizadores sobre áreas rurales y localidades menores.

Se entiende que las localidades intermedias pueden y deben desempeñar un papel más activo frente a las asimetrías territoriales derivadas de una particular distribución socioterritorial, equilibrando los procesos de polarización y compensando, e incluso frenando, el excesivo crecimiento de las grandes aglomeraciones urbanas. Dadas sus importantes potencialidades, las localidades intermedias resultan cruciales a la hora de repensar las políticas de desarrollo regional en Argentina y deberían, por lo tanto, ser tenidas en cuenta como centros privilegiados en cualquier intento de revitalización de las economías regionales desde una perspectiva territorial. Ahora bien, en la búsqueda de ese objetivo -que podríamos denominar de reequilibrio territorialdebe tenerse en cuenta el funcionamiento de los diferentes sistemas urbanos, así como las potencialidades y roles que juegan los diferentes núcleos en cada contexto regional. En ese sentido, se podría señalar que contribuyen a mantener la población rural en esas áreas alejadas proporcionándoles servicios y, a veces, empleos.

A partir de revisar las distintas definiciones y debates, interesa poner en cuestión la conceptualización de las denominadas localidades intermedias y avanzar en respuesta a interrogantes como ¿cuál es la dinámica del sistema urbano-regional argentino y en particular de las localidades intermedias a partir de mediados del siglo pasado?, ¿Cuáles son las causas que originan las distintas dinámicas?

El trabajo se organiza con un primer apartado en el que se remite a la relación entre el sistema urbano y su relación con los modelos de desarrollo y los aspectos que permiten definir las ciudades intermedias. En un segundo momento, se analiza la dinámica demográfica que fueron transitando los aglomerados ${ }^{1}$ intermedios del sistema regional urbano argentino. Luego, se avanza en dos estudios de caso de ciudades intermedias, uno que ha tenido una dinámica poblacional positiva y otro uno negativa en relación al contexto nacional: se trata de Ushuaia (Tierra del Fuego) y de Pergamino (Buenos Aires). Finalmente, se extraen algunas consideraciones sobre el análisis realizado.

\section{EL DEBATE EN CUESTIÓN}

Para pensar un sistema de ciudades o localidades, no se puede dejar de considerar al territorio en su complejidad, considerando una multiplicidad de dimensiones, incluyendo el análisis del proceso de su configuración, así como también el sentido en que se piensa su desarrollo económico y territorial a partir de los planes, proyectos y políticas de ordenamiento territorial que inciden en su conformación. Es decir, que, no se puede pensar el territorio y las aglomeraciones urbanas que lo integran en forma desarticulada del modelo de desarrollo.

En este sentido, los modelos históricos de desarrollo de la Argentina han dejado su huella en la organización territorial. Durante la colonia, se tendió al fortalecimiento de los núcleos hacia Lima y luego hacia Buenos Aires. Luego, con la implementación del modelo económico agroexportador, se multiplicaron las infraestructuras en las áreas más fértiles de la llanura pampeana, para llevar la producción a los puertos y facilitar su exportación. A su vez, el modelo de sustitución de importaciones que lo sucedió, produjo un acelerado crecimiento de los núcleos urbanos de gran tamaño en donde se radicaron las mayores industrias convocantes de mano de obra. De este modo, todos los modelos de desarrollo implicaron una determinada forma de ocupación y producción del territorio y con ello, el crecimiento (o no) de particulares núcleos y áreas que lo conforman. En Palabras de Carlos De Mattos (1984) no se puede pensar la organización del territorio con un "razonamiento excesivamente apegado a la dimensión territorial y, por consiguiente, caracterizado por una tendencia a subvalorar, en mayor o menor medida, según los casos, el peso de las condiciones y restricciones inherentes a la lógica de los modelos dominantes de acumulación a escala nacional" (De Mattos, 1984:28).

\footnotetext{
${ }^{1}$ Se toma la categoría de aglomerado como unidad observable para el trabajo sobre las ciudades intermedias, con particulares características geo-estadísticas definidas por el Instituto Nacional de Estadística y Censos de la República Argentina. Se entiende por aglomerado a una extensión urbana continua, compuesta por una o más localidades censales, por uno o más gobiernos locales, comprendida en una o más provincias. El aglomerado hace referencia a la ciudad real, a la mancha urbana que funciona en conjunto, independientemente de su pertenencia a una o más jurisdicciones.
} 
En las últimas décadas, de la mano de la reestructuración económica y de la mundialización de la economía, y gracias al desarrollo de las nuevas tecnologías de la información y comunicación, se han generado cambios en la forma de organizar la producción y el trabajo, en donde la contigüidad física pasó a cobrar un peso relativo. El nuevo sistema industrial propuso entonces una nueva articulación de dinámicas globales y locales en las configuraciones urbano-regionales. Al respecto, Castells (1996) se refiere a los patrones de localización flexible que comenzaron a adoptar las industrias de alto contenido tecnológico, descentralizando sus sistemas de producción en una cadena global de división espacial del trabajo mediante la segmentación espacial de la producción. Desde esta perspectiva, la delimitación del espacio no se explica por su continuidad geográfica sino que lo hace por la continuidad de procesos entrelazados funcionalmente. Entonces, los procesos socioeconómicos dominantes, organizados en una red global: en el espacio de los flujos, inciden en la producción y conformación del territorio (Castells, 1996).

Estos cambios implicaron una tendencia a la especialización y complementación de ciudades que ofrecen nuevos tipos de servicios y que se acompañó con una creciente descentralización de funciones de gobierno. Por otro lado, se ha producido una mayor accesibilidad en múltiples modos de transporte, pero su distribución es altamente inequitativa, favoreciendo sólo a determinados nodos y sectores sociales. Estos factores, han afectado la dinámica de las localidades, de los sistemas urbanos y la conformación de la jerarquía urbana de todo el globo, generando impactos económicos, sociales, políticos y culturales. En este sentido, puede afirmarse que el proceso de globalización es asimétrico y excluyente en la medida que conecta unos territorios al tiempo que aísla otros, priorizando ciertos flujos de bienes, servicios, información, personas y capital que se concentran en un conjunto de áreas específicas. Son impactos heterogéneos, en lo que Benko y Lipietz analizaron como regiones que ganan y otras que pierden.

Otro de los efectos notorios que ha implicado la globalización es, sin duda, la multiplicidad de relaciones que establecen los actores a lo largo y a lo ancho del planeta, atravesando las fronteras físicas y políticas. Así, muchas ciudades pasaron a mantener relaciones económicas más fuertes con localidades por fuera de su área de influencia regional y nacional, que con otras localidades más cercanas.

Como menciona Llop (1999), el proceso de globalización que tiende a favorecer a las ciudades globales y a las principales metrópolis, castiga a las ciudades intermedias. Sin embargo, para algunas de ellas, el mismo proceso puede representar una oportunidad de integración a las nuevas redes de flujos en la medida que el tamaño poblacional no es un requerimiento para ello. Sí lo es su localización geográfica, su posición en el entramado global y sus posibilidades de intercambio de recursos, bienes y servicios. Así, para las ciudades intermedias latinoamericanas, las oportunidades de inclusión a la red global son menores que para las ciudades intermedias de América del Norte o de Europa, al tiempo que las condiciones de los términos intercambio, mucho más desfavorables, hecho que refuerza aún más las diferencias entre ellas.

En este contexto, en el cual prima una dinámica diferencial y excluyente entre los núcleos urbanos y en el acceso a bienes y servicios, es que se precisa avanzar en la conceptualización sobre sistemas urbanos y regionales y -dentro de ellos- en el rol de las localidades intermedias con la finalidad de alcanzar un territorio más equilibrado.

Podemos entonces señalar, que los sistemas urbanos-regionales están integrados por asentamientos de población relacionados mediante vías e infraestructuras de transporte y que dentro de ellos, los núcleos urbanos sirven como centros de servicios a otros nodos y a espacios rurales. El análisis de esas interrelaciones y de los servicios presentes en los distintos centros, permite evaluar el funcionamiento -en un determinado territorio- de las condiciones para el asentamiento de la población y para el desarrollo de actividades productivas. Su estudio es útil también para pensar una imagen de territorio deseado ${ }^{2} \mathrm{y}$, en función de ello, para diseñar políticas territoriales, atendiendo a demandas no cubiertas.

Entendiendo que existen centros con distintas ofertas para el desarrollo de actividades y el asentamiento de la población, dentro del análisis de los sistemas urbanos-regionales se vuelve relevante la jerarquización de los centros urbanos según el grado en que prestan servicios a sus entornos regionales. La ausencia de localidades en amplias zonas supone la carencia de equipamientos y la marginación del sistema productivo (Capel; 2003). Acordando con ello, se entiende que la identificación y jerarquización de los asentamientos urbanos es un tema esencial en la fase de análisis territorial para definir el modelo territorial actual y constituye

2 El territorio o el modelo de territorio deseado, es una imagen objetivo que se pretende lograr en ese ámbito espacial a través de la implementación de un conjunto de estrategias y de la concreción de proyectos. 
una de las condiciones para la formulación de un modelo territorial más equilibrado ${ }^{3}$, entendiendo que esto no significa la distribución homogénea de equipamientos y de servicios sino que la misma debe ser acorde a las particularidades de cada porción territorial en cuanto a la potencialidad para el desarrollo de actividades, a políticas de ocupación del territorio con más contención de políticas públicas o incluso, en algunos casos, a decisiones geopolíticas.

Dentro de los sistemas urbanos regionales, se rescata el rol de las localidades intermedias en la prestación de servicios para el desarrollo de un territorio más equilibrado. Son localidades ofrecen empleos, servicios e infraestructura colectiva a la población urbana y regional, funcionan como mercados locales para sus productos, cumplen un rol de integración de flujos (Hildreth, 2006); permiten el acceso a servicios tales como educación universitaria o tratamientos médicos de gran complejidad; son centros de interacción social, económica y cultural, y a decir de Hardoy y Satterthwaite, son el corazón de áreas rurales en el Tercer Mundo (Hardoy y Satterthwaite 1987). Organizan el territorio a la vez que integran redes de asentamientos interdependientes, no son sólo entre asentamientos de un mismo territorio nacional, sino que en ocasiones su influencia traspasa fronteras internacionales.

Las dimensiones de la población de las localidades intermedias son muy diversas, varían históricamente y para cada país. Pero más allá de la cantidad de habitantes, interesa definir las localidades intermedias según criterios que den cuenta de la prestación de servicios y las condiciones para el asentamiento de la población y la radicación de actividades, y de la atracción que genera de su entorno. Algunas localidades pertenecen a más de un sistema urbano, pero también desempeñan un papel importante como cabezas de ciertas cadenas de producción agroindustriales del país, revisten vocación turística para el turismo interno y externo, son centros de servicios especializados, etc., particularidades que hacen que los sistemas urbanos sean dinámicos y flexibles, que se puedan identificar en relación a particulares procesos de las actividades productivas y de la población.

La ciudad media-intermedia, entonces, no puede definirse solo por su tamaño sino que debe incluirse la función que la misma juega en su territorio más o menos inmediato, la influencia y relación que ejerce y los flujos y relaciones que genera hacia el exterior. La ciudad intermedia no se define de manera intrínseca, sino que se constituye en relación, como nodo que intermedia entre espacios rurales y urbanos comprendidos en su sistema regional-urbano de pertenencia.

Algunas de las características que ayudan a definir el rol de una ciudad intermedia en su territorio de influencia, se centran en su capacidad de ofrecerse como centros servidores de bienes y servicios más o menos especializados, y/o de interacción social, económica y cultural, y/o centros ligados a redes de infraestructuras que conectan las redes locales, regionales y nacionales e incluso, algunas, con fácil acceso a las internacionales, y /o aquellos centros donde se localiza la administración de gobiernos locales.

\section{LAS CIUDADES INTERMEDIAS EN EL SISTEMA URBANO-REGIONAL ARGENTINO}

En las últimas décadas, han acaecido notables transformaciones en los esquemas de los asentamientos humanos a escala mundial, con una creciente tasa de población urbana. Argentina no es ajena a estos procesos, el país presenta un alto nivel de urbanización, 91,2\% según el INDEC en 2010, y una estructura regional urbana que evidencia un sistema centralizado en el Gran Buenos Aires -aglomerado de gran primacía urbana- y en otros pocos aglomerados (de menor peso demográfico) que se destacan sobre un conjunto de localidades menores ${ }^{4}$. Además, se distinguen subsistemas regionales que muestran desequilibrios, con centros urbanos de escasa jerarquía y complejidad funcional y pocos incentivos para la radicación de población. La distribución territorial de la población reflejada en el Censo Nacional de Población, Hogares y Viviendas de 2010 (CNPHV 2010) da cuenta de la sensible concentración demográfica en el Gran Buenos Aires, sólo este aglomerado ${ }^{5}$ acumuló casi un tercio $(33,9 \%)$ de la población total del país y prácticamente iguala la suma de la población de los 45 aglomerados que le siguen en tamaño. En el Cuadro 1 se clasificaron los aglomerados por rangos poblacionales, en donde el salto más grande se produce justamente entre el

\footnotetext{
${ }^{3}$ En la Argentina existen numerosos antecedentes académicos de análisis de sistemas regionales de asentamientos por diferenciación funcional. Un primer estudio, de 1984, fue elaborado por la Subsecretaría de Vivienda y Ordenamiento Ambiental se elaboró un documento en el marco del Plan Nacional de Vivienda 1984-1989, que abarcó al conjunto de localidades del país de más de 2.000 habitantes (SVOA, 1984).

${ }^{4}$ Si bien nos referimos como término a "localidades intermedias", al analizar sus características desde su funcionalidad, trabajamos con el aglomerado del cual forma parte.

${ }^{5}$ Se entiende por aglomerado a una extensión urbana continua, compuesta por una o más localidades censales, por uno o más gobiernos locales, comprendida en una o más provincias. El aglomerado hace referencia a la ciudad real, a la mancha urbana que funciona en conjunto, independientemente de su pertenencia a una o más jurisdicciones.
} 
rango superior -compuesto únicamente por el Gran Buenos Aires-y el rango que le sigue, en tanto el segundo aglomerado en cantidad de población condensa sólo el 10,7\% de la población del primero. Dentro del tercer rango, aglomerados entre 500.000 hasta el millón de habitantes, hay 5 localidades, que son las que presentan mayores saltos poblacionales entre sí al interior de su grupo, de hasta casi 200.000 habitantes de diferencia entre una y otra. A partir del cuarto rango (200.000 a 499.999 hab.) los valores son más homogéneos, aumentando esa característica a medida que la población disminuye.

\begin{tabular}{|c|c|c|c|c|c|c|c|c|}
\hline \multirow{2}{*}{$\begin{array}{l}\text { Rango de Población } \\
\text { por aglomerado }\end{array}$} & \multicolumn{3}{|c|}{ Aglomerados } & \multicolumn{2}{|c|}{ Población } & \multicolumn{3}{|c|}{$\begin{array}{l}\text { Incidencia en el conjunto } \\
\text { de la población nacional }\end{array}$} \\
\hline & Cant. & Cant. acum. & & Sant. & Cant. acum. & Participación (\%) & Acum. (\%) & \\
\hline más de 5.000 .000 & 1 & & 1 & 13.588 .171 & 13.588 .171 & 33,9 & & 33,9 \\
\hline 1.000 .000 a 4.999 .999 & 2 & & 3 & 2.690 .734 & 16.278 .905 & 6,7 & & 40,6 \\
\hline 500.000 a 999.999 & 5 & & 8 & 3.663 .168 & 19.942 .073 & 9,1 & & 49,7 \\
\hline 200.000 a 499.999 & 11 & & 19 & 3.792 .872 & 23.734 .945 & 9,5 & & 59,2 \\
\hline 50.000 a 199.999 & 50 & & 69 & 4.719 .536 & 28.454 .481 & 11,8 & & 71 \\
\hline 20.000 a 49.999 & 106 & & 175 & 3.216 .180 & 31.670 .661 & 8 & & 79 \\
\hline 10.000 a 19.999 & 145 & & 320 & 2.041 .133 & 33.711 .794 & 5,1 & & 84,1 \\
\hline 5.000 a 9.999 & 229 & & 549 & 1.607 .383 & 35.319 .177 & 4 & & 88,1 \\
\hline 2.000 a 4.999 & 377 & & 926 & 1.217 .292 & 36.536 .469 & 3 & & 91,1 \\
\hline Menos de 1.999 & & & & 3.580 .627 & 40.117 .096 & 8,9 & & 100 \\
\hline
\end{tabular}

Cuadro 1 - Cantidad de población y aglomerados por rangos de población por aglomerado s/CNPHV 2010

Elaboración propia en base a Censo Nacional de Población, Hogares y Vivienda 2010

En relación a la cantidad de aglomerados comprendidos en cada rango poblacional, destaca por sobre el resto la cantidad de nodos urbanos que presentan entre 2.000 y 4.999 habitantes, seguido por los nodos que condensan entre 5.000 a 9.999 pobladores. En este caso, se presenta una relación inversa entre cantidad de aglomerados y tamaño de los mismos, es decir, a menor rango poblacional es mayor la cantidad de aglomerados, y viceversa, a mayor rango poblacional menor cantidad de aglomerados. De los 926 aglomerados censados en el año 2010, el 40,7\% detentaban entre 2.000 y 4.999 habitantes (rango inferior) y el $81,1 \%$ de los mismos tiene menos de 20.000 habitantes.

En cuanto a la distribución de población según el tamaño del aglomerado de residencia, se observa que la mitad reside en aglomerados de más de 500.000 habitantes, y el $71 \%$ en aglomerados de más de 50.000 habitantes. En localidades de menos de 20.000 habitantes reside sólo el 21\% de la población del país, incluyendo población rural y urbana. Luego del rango que comprende al Gran Buenos Aires, el que le sigue en cuanto a incidencia en el conjunto de la población nacional es el comprendido entre 50.000 y 199.999 habitantes, sobre el cual haremos foco a continuación.
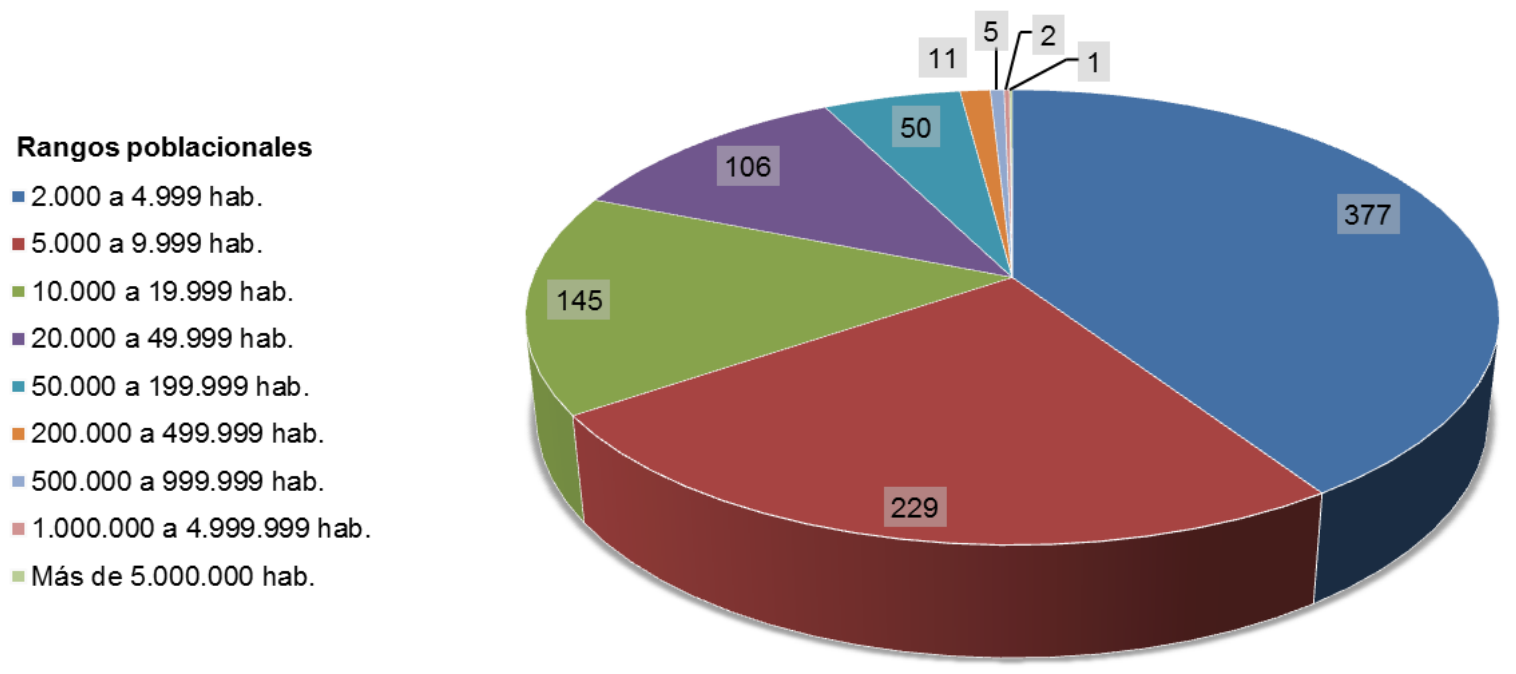

Gráfico 1 - Cantidad de aglomerados por rangos de población s/CNPHV 2010

Fuente: Elaboración propia en base a Censo Nacional de Población, Hogares y Vivienda 2010 
Rangos poblacionales

- Más de 5.000.000 hab.

- 50.000 a 199.999 hab.

- 200.000 a 499.999 hab

- 500.000 a 999.999 hab

- Menos de 1.999 hab.

= 20.000 a 49.999 hab.

$=1.000 .000$ a $4.999 .999 \mathrm{hab}$

॥ 10.000 a 19.999 hab.

$=5.000$ a 9.999 hab.

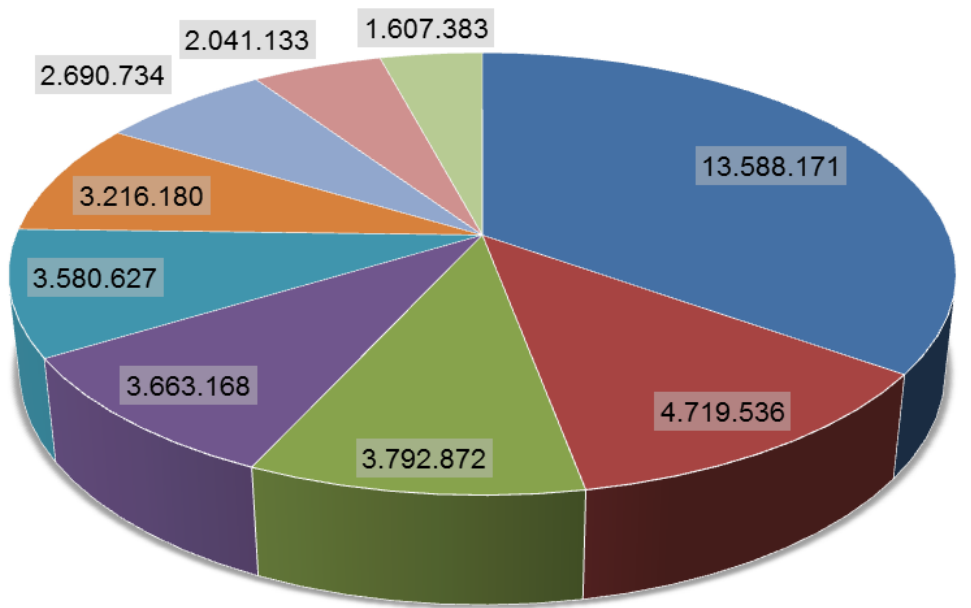

Gráfico 2 - Cantidad de habitantes por rangos de población s/CNPHV 2010

Fuente: Elaboración propia en base a Censo Nacional de Población, Hogares y Vivienda 2010

Si bien se entiende que el criterio para definir a las ciudades intermedias debería estar ligado a su funcionalidad (principalmente económica y de prestación de servicios) dentro del sistema regional urbano más que a su tamaño poblacional, a los efectos del presente análisis, provisoriamente calificaremos a las mismas como aquellas que comprendieron entre 50.000 y 200.000 habitantes en el último censo ${ }^{6}$.

Entonces, habiendo acotado el universo de análisis según ese criterio poblacional, de los 926 aglomerados registrados en el CNPHV 2010 (más de 2.000 habitantes), se trabajará sólo con los 50 ubicados en ese rango -provisoriamente calificados como ciudades intermedias-, que suman en total 4.606 .418 habitantes. En cuanto a la distribución geográfica, se destaca la prevalencia de la Provincia de Buenos Aires por sobre el resto, condensando 12 de las 50 ciudades intermedias de Argentina y el 21,3\% de la población que habita en ellas.

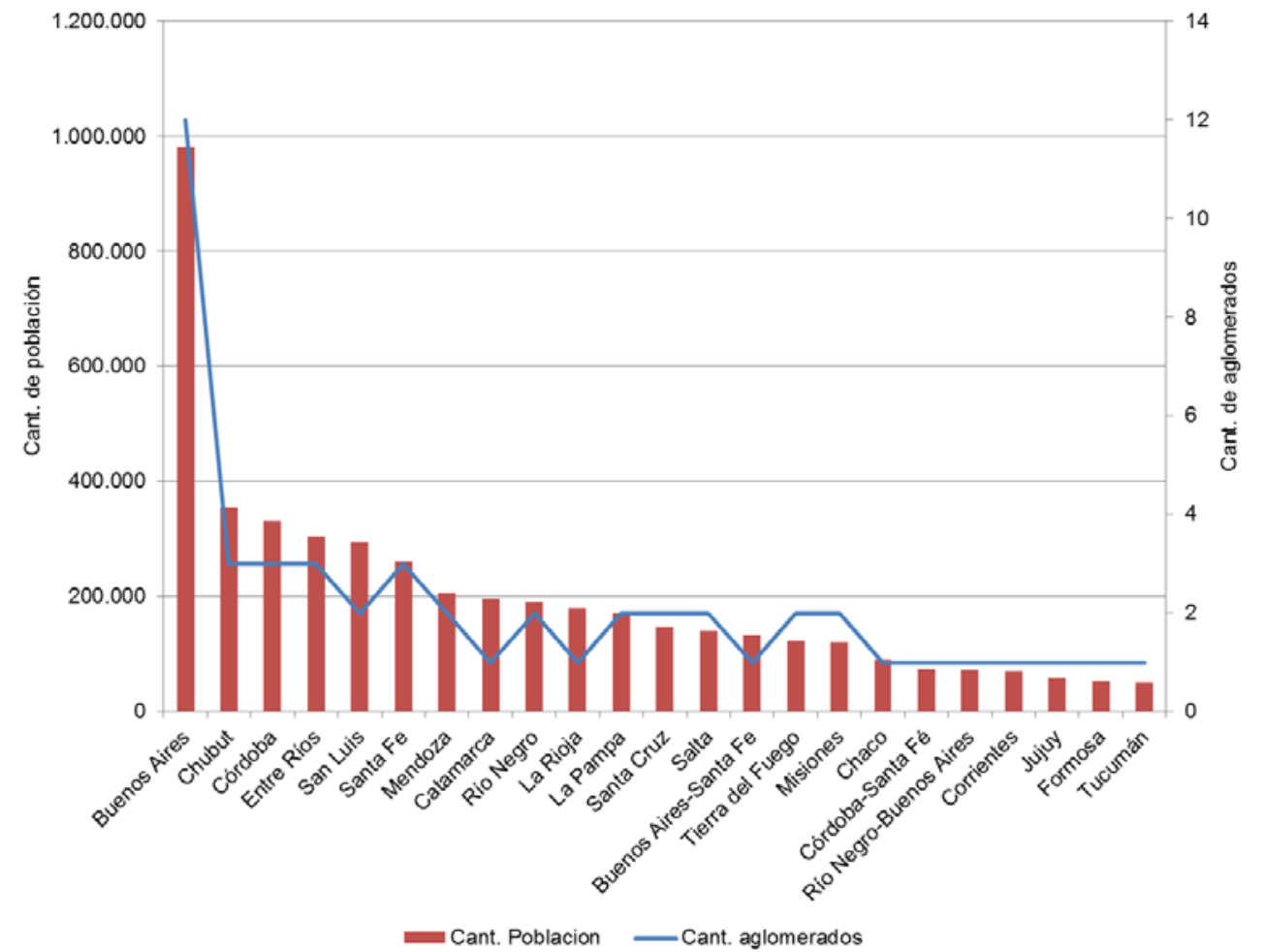

Gráfico 3 - Cantidad de aglomerados intermedios y suma de habitantes por Provincia s/CNPHV 2010 Fuente: Elaboración propia en base a Censo Nacional de Población, Hogares y Vivienda 2010

\footnotetext{
${ }^{6}$ Este trabajo forma parte de uno mayor, en donde se prevé, luego de diseñar variables e indicadores de permitan inferir cuestiones funcionales, definir las ciudades intermedias en Argentina. De todas formas, y como primera aproximación, se entiende que la complejidad mínima para ese tipo de localidades no estaría emplazada en aquellos núcleos de menos de 50.000 habitantes.
} 
El crecimiento relativo de los aglomerados intermedios (50.000 a 200.000 habitantes según CNPHV 2010) aconteció por encima de los promedios nacionales desde 1980 hasta 2010:

- Entre 1980 y 1991, mientras que a nivel país la variación intercensal relativa de población fue de $16,7 \%$, en los aglomerados intermedios fue de $31,8 \%$.

- Entre 1991 y 2001 el promedio nacional registró un 12,2\% de crecimiento frente a un 18,4\% de los aglomerados intermedios.

- Entre 2001 y 2010 el crecimiento a nivel país fue de 10,6\% contra el 14,2\% de los núcleos urbanos de interés.

El desacople más sensible de los aglomerados intermedios respecto de las dinámicas nacionales fue entre 1980-1991, en coincidencia con las leyes promoción industrial (en particulares provincias) que comenzaron en los años 70 y se expandieron en los años 80 del siglo pasado, a la vez que el proceso de desindustrialización fue haciendo mella en las ciudades con fuerte perfil industrial.

En coincidencia con los datos antes mencionados, la distribución de la población por aglomerados en los censos nacionales de los años 1980, 1991, 2001 y 2010 muestra una creciente incidencia de los aglomerados intermedios en el promedio nacional. En 1980 estos representaron el 9,2\% de la población total del país, en 1991 el 10,4\%, en 2001 el 11,1\% y en 2010 el 11,4\%. Junto a ello fue perdiendo incidencia en el conjunto nacional el aglomerado más grande: el Gran Buenos Aires condensaba el 42,37\% de la población del país en 1980, el 39,46\% en 1991, el 37,23\% en 2001 y el 33,9\% en 2010. Si bien los aglomerados intermedios han presentado una dinámica de crecimiento relativo mayor que el Gran Buenos Aires, cabe aclararse que ello no implica un mayor crecimiento en términos absolutos, debido a la heredada primacía urbana de este último aglomerado.

En cuanto a la distribución espacial del crecimiento de los aglomerados intermedios, en líneas generales se observa un crecimiento relativo a favor de los aglomerados alejados de los principales centros de producción y consumo. Un caso extremo de ello es Tierra del Fuego, que lidera ampliamente el crecimiento relativo de sus aglomerados intermedios entre 1980-1991, y también entre 1991-2001, aunque con menor diferencial. Entre 2001-2010, Tierra del Fuego (25,4\%) fue sólo superada por otras dos provincias de la Patagonia Argentina, Santa Cruz $(28,9 \%)$ y Chubut $(25,9 \%)$. Por otro lado, Buenos Aires, que registró la mayor cantidad de aglomerados intermedios y la mayor cantidad de población que los habita, fue la Provincia cuyos aglomerados intermedios crecieron menos en términos relativos. Al respecto, se destaca que desde la década del 80', en líneas generales, las Provincias más pobladas del país, resultan menos dinámicas en términos del crecimiento relativo de sus aglomerados intermedios.

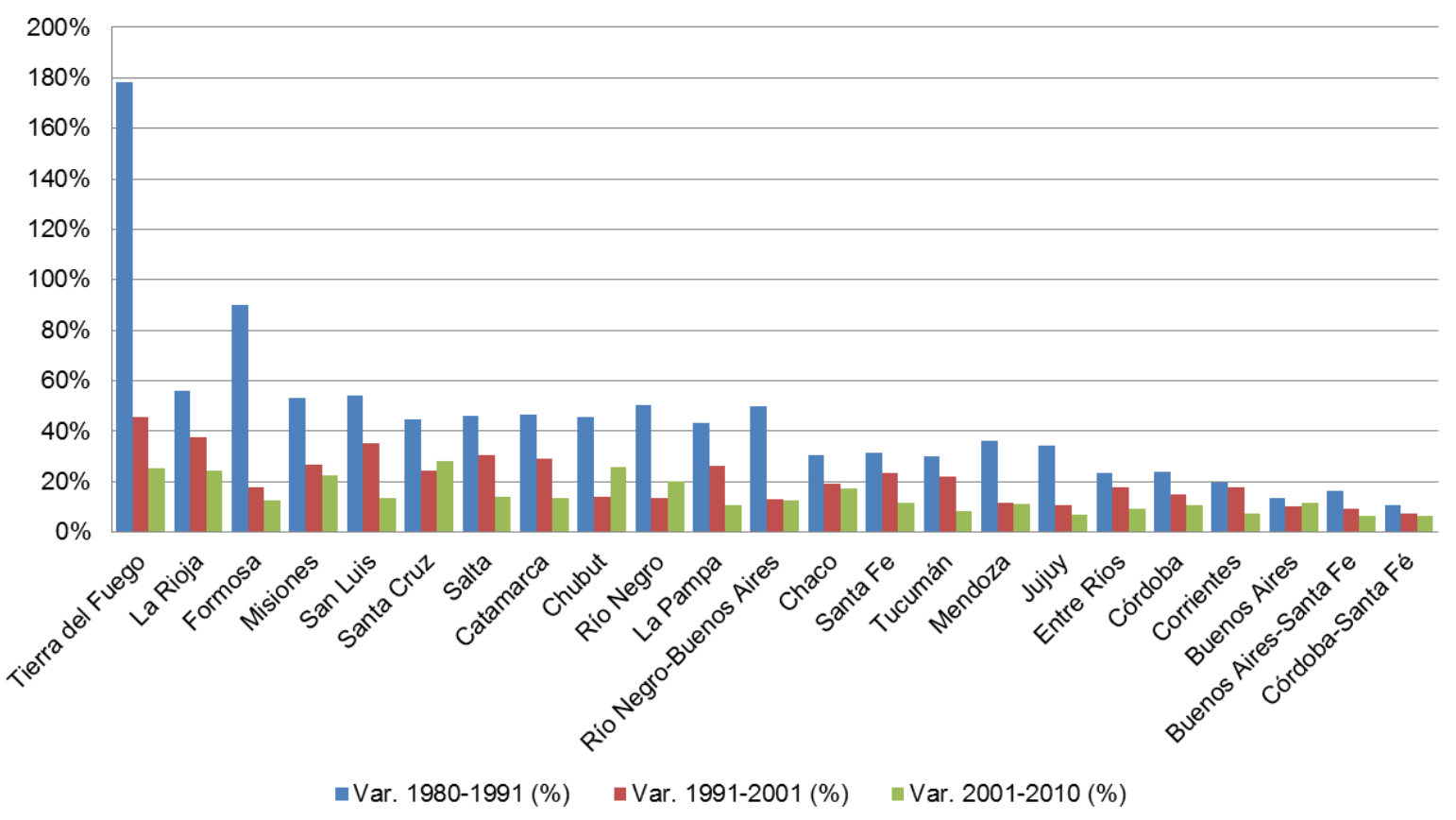

Gráfico 4 - Variación intercensal relativa de aglomerados intermedios, por Provincia s/CNPHV 1980-1991-2001-2010 Elaboración propia en base a Censo Nacional de Población, Hogares y Vivienda 1980-1991-2001-2010 
Los tres aglomerados que más crecieron en términos relativos entre 1980-2010, y que además se desprenden notablemente del cuarto aglomerado, son de la Patagonia: dos pertenecen a Tierra del Fuego y otro a Chubut. El que más creció porcentualmente fue Ushuaia con un crecimiento del $413 \%$ entre 1980-2010, que en términos absolutos pasó de condensar 11.029 habitantes en 1980 a 56.593 en 2010. Por su parte, en el segundo en crecimiento relativo fue Río Grande, con un patrón de crecimiento muy similar a Ushuaia en términos absolutos y relativos. El tercer aglomerado en cuanto a crecimiento relativo 1980-2010 fue Puerto Madryn, en la Provincia de Chubut. Los tres aglomerados tuvieron un fuerte crecimiento entre 1980-1991, de 167\% Ushuaia, de 187\% Río Grande y de 120\% Puerto Madryn, en algunos casos por la incidencia de actividades turísticas y en otros por la localización de actividades industriales amparadas por la leyes de promoción.

De los diez aglomerados que menos crecieron entre 1980-2010, ocho se ubicaron en la Provincia de Buenos Aires, uno entre Buenos Aires-Santa Fe y el restante entre Córdoba-Santa Fe. En cuanto a los aglomerados más estancados (no hay decrecimientos poblacionales), se destaca el caso de Punta Alta, en la Provincia de Buenos Aires, que creció sólo un 4\% entre 1980 y 2010, diferenciándose fuertemente de las dinámicas del resto de los aglomerados ya que el segundo (Azul, Provincia de Buenos Aires) que menos creció lo hizo en un $26 \%$.

En relación a dinámicas diferenciadas para los aglomerados intermedios que para el CNPHV 2010 tenían entre 50.000 y 100.000 y los que presentaron entre 100.000 y 200.000 , se observa que el crecimiento relativo de ambos estratos poblacionales entre el año 1980 y el 2010 ha sido levemente a favor del estrato superior (100.000 a 200.000 hab.), con un $85,6 \%$ de crecimiento frente a un $74 \%$ del estrato inferior. Sin embargo, es posible observar dinámicas diferenciadas entre 1980-1991 y entre 1991-2001. Entre 1980-1991 tuvieron un mayor crecimiento relativo los aglomerados que en el CNPHV 2010 registraron ente 50.000 y 100.00 habitantes, con un $30,3 \%$ frente a un $18,1 \%$ del estrato mayor. La tendencia se revirtió de una década a la otra, en tanto que entre 1991-2001 las localidades que registraron entre 100.000 habitantes y 200.000 en el CNPHV 2010 crecieron por encima del estrato inferior, con un $36,8 \%$ frente a un $17,4 \%$ respectivamente. Finalmente, entre $2001-2010$ el crecimiento de ambos estratos fue parejo con un $14,9 \%$ del estrato superior y un $13,8 \%$ del estrato inferior.

Finalmente, en cuanto a las dinámicas demográficas de los aglomerados intermedios entre 1980 y 2010 , se destaca que el crecimiento de este tipo de núcleos urbanos, en términos relativos, ha sido siempre por encima del promedio del país y del Gran Buenos Aires, incrementando su incidencia en el total de la población nacional censo tras censo. Se ha visto que desde el año 1980 hasta el año 2010 la población urbana de aglomerados intermedios se concentra de manera incremental, en términos relativos, en las Provincias menos pobladas del país y más alejadas de los principales centros de producción y consumo; al punto que los menos dinámicos han sido los de la Provincia de Buenos Aires. Si bien las variaciones relativas no tienen un correlato con las variaciones absolutas, este proceso podría representar un camino hacia la desconcentración urbana. 


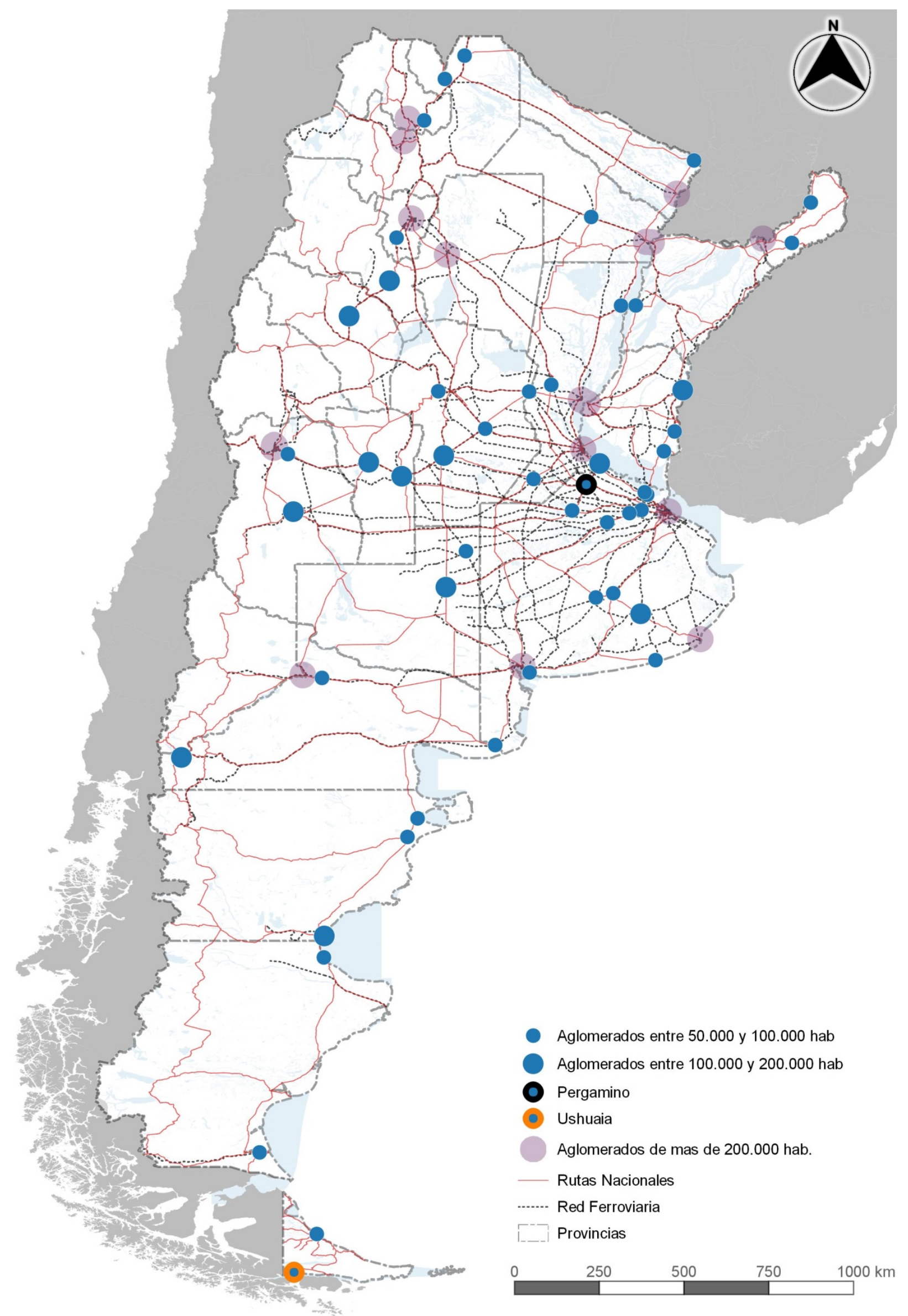

Mapa 1 - Aglomerados intermedios en el sistema urbano-regional argentino

Elaboración propia en base a Censo Nacional de Población, Hogares y Vivienda 2010 y datos publicados por el IGN (SIG250) 


\begin{tabular}{|c|c|c|c|c|c|c|c|c|c|}
\hline Provincia & Aglomerado & Pobl. 1980 & Pobl. 1991 & Pobl. 2001 & Pobl. 2010 & \begin{tabular}{|l} 
Var. \% \\
$1980-$ \\
1991 \\
\end{tabular} & \begin{tabular}{|l} 
Var. \% \\
1991- \\
2001 \\
\end{tabular} & \begin{tabular}{|l} 
Var. \% \\
2001- \\
2010
\end{tabular} & $\begin{array}{l}\text { Var. \% } \\
1980- \\
2010\end{array}$ \\
\hline Córdoba & Gran Río Cuarto & 113.190 & 138.996 & 149.303 & 163.048 & $22,8 \%$ & $7,4 \%$ & $9,2 \%$ & $44,0 \%$ \\
\hline Catamarca & $\begin{array}{l}\text { Gran San Fernando del Valle de } \\
\text { Catamarca }\end{array}$ & 90.851 & 133.050 & 171.923 & 195.055 & $46,4 \%$ & $29,2 \%$ & $13,5 \%$ & $114,7 \%$ \\
\hline Chubut & Comodoro Rivadavia & 96.817 & 124.151 & 135.632 & 175.196 & $28,2 \%$ & $9,2 \%$ & $29,2 \%$ & $81,0 \%$ \\
\hline Entre Ríos & Concordia & 94.222 & 116.491 & 138.099 & 149.450 & $23,6 \%$ & $18,5 \%$ & $8,2 \%$ & $58,6 \%$ \\
\hline \begin{tabular}{|l|} 
Buenos Aires- \\
Santa Fe
\end{tabular} & $\begin{array}{l}\text { San Nicolás de los Arroyos - } \\
\text { Barrio Arroyo del Medio }\end{array}$ & 98.495 & 114.752 & 125.408 & 133.602 & $16,5 \%$ & $9,3 \%$ & $6,5 \%$ & $35,6 \%$ \\
\hline San Luis & Gran San Luis & 73.404 & 114.518 & 162.011 & 182.414 & $56,0 \%$ & $41,5 \%$ & $12,6 \%$ & $148,5 \%$ \\
\hline La Rioja & La Rioja & 67.043 & 104.494 & 143.684 & 178.872 & $55,9 \%$ & $37,5 \%$ & $24,5 \%$ & $166,8 \%$ \\
\hline Mendoza & San Rafael & 72.759 & 94.776 & 106.386 & 118.009 & $30,3 \%$ & $12,2 \%$ & $10,9 \%$ & $62,2 \%$ \\
\hline Buenos Aires & Tandil & 79.429 & 90.427 & 101.010 & 116.916 & $13,8 \%$ & $11,7 \%$ & $15,7 \%$ & $47,2 \%$ \\
\hline La Pampa & Gran Santa Rosa & 55.306 & 80.629 & 102.399 & 114.486 & $45,8 \%$ & $27,0 \%$ & $11,8 \%$ & $107,0 \%$ \\
\hline Córdoba & Villa María - Villa Nueva & 67.560 & 78.666 & 88.643 & 98.169 & $16,4 \%$ & $12,7 \%$ & $10,7 \%$ & $45,3 \%$ \\
\hline Buenos Aires & Pergamino & 68.612 & 78.200 & 85.487 & 91.399 & $14,0 \%$ & $9,3 \%$ & $6,9 \%$ & $33,2 \%$ \\
\hline Chubut & Trelew & 52.372 & 78.089 & 88.305 & 97.915 & $49,1 \%$ & $13,1 \%$ & $10,9 \%$ & $87,0 \%$ \\
\hline Buenos Aires & Zárate & 67.143 & 77.877 & 86.686 & 98.522 & $16,0 \%$ & $11,3 \%$ & $13,7 \%$ & $46,7 \%$ \\
\hline Río Negro & San Carlos de Bariloche & 48.980 & 77.750 & 89.092 & 109.305 & $58,7 \%$ & $14,6 \%$ & $22,7 \%$ & $123,2 \%$ \\
\hline San Luis & Villa Mercedes & 50.992 & 77.137 & 96.781 & 111.391 & $51,3 \%$ & $25,5 \%$ & $15,1 \%$ & $118,4 \%$ \\
\hline Buenos Aires & Necochea - Quequén & 62.843 & 73.833 & 79.983 & 84.784 & $17,5 \%$ & $8,3 \%$ & $6,0 \%$ & $34,9 \%$ \\
\hline Buenos Aires & Olavarría & 64.374 & 72.821 & 83.738 & 89.721 & $13,1 \%$ & $15,0 \%$ & $7,1 \%$ & $39,4 \%$ \\
\hline Mendoza & San Martín - La Colonia & 49.349 & 71.593 & 79.662 & 88.879 & $45,1 \%$ & $11,3 \%$ & $11,6 \%$ & $80,1 \%$ \\
\hline Buenos Aires & Junín & 62.458 & 70.138 & 82.427 & 87.509 & $12,3 \%$ & $17,5 \%$ & $6,2 \%$ & $40,1 \%$ \\
\hline Buenos Aires & Campana & 53.994 & 67.267 & 77.838 & 86.860 & $24,6 \%$ & $15,7 \%$ & $11,6 \%$ & $60,9 \%$ \\
\hline Santa Fé & Rafaela & 53.273 & 67.086 & 82.416 & 91.571 & $25,9 \%$ & $22,9 \%$ & $11,1 \%$ & $71,9 \%$ \\
\hline \multirow{2}{*}{$\begin{array}{l}\text { Buenos Aires } \\
\text { Córdoba-Santa } \\
\text { Fé }\end{array}$} & Luján & 57.223 & 66.226 & 67.266 & 97.363 & $15,7 \%$ & $1,6 \%$ & $44,7 \%$ & $70,1 \%$ \\
\hline & San Francisco - Frontera & 58.536 & 64.779 & 69.522 & 74.060 & $10,7 \%$ & $7,3 \%$ & $6,5 \%$ & $26,5 \%$ \\
\hline Santa Cruz & Río Gallegos & 43.727 & 64.628 & 79.144 & 95.796 & $47,8 \%$ & $22,5 \%$ & $21,0 \%$ & $119,1 \%$ \\
\hline Entre Ríos & $\begin{array}{l}\text { Gualeguaychú - Pueblo General } \\
\text { Belgrano }\end{array}$ & 0 & 64.620 & 75.516 & 82.644 & $25,7 \%$ & $16,9 \%$ & $9,4 \%$ & $60,8 \%$ \\
\hline Chaco & Presidencia Roque Sáenz Peña & 49.341 & 64.476 & 76.794 & 89.882 & $30,7 \%$ & $19,1 \%$ & $17,0 \%$ & $82,2 \%$ \\
\hline Santa Fe & Reconquista - Avellaneda & 43.021 & 63.353 & 82.892 & 93.890 & $47,3 \%$ & $30,8 \%$ & $13,3 \%$ & $118,2 \%$ \\
\hline Río Negro & General Roca & 44.039 & 61.896 & 69.672 & 81.534 & $40,5 \%$ & $12,6 \%$ & $17,0 \%$ & $85,1 \%$ \\
\hline Santa Fe & Venado Tuerto & 47.501 & 58.678 & 68.426 & 75.437 & $23,5 \%$ & $16,6 \%$ & $10,2 \%$ & $58,8 \%$ \\
\hline \begin{tabular}{|l|} 
Río Negro - \\
Buenos Aires \\
\end{tabular} & Viedma - Carmen de Patagones & 38.442 & 57.651 & 65.137 & 73.322 & $50,0 \%$ & $13,0 \%$ & $12,6 \%$ & $90,7 \%$ \\
\hline Corrientes & Goya & 47.357 & 56.720 & 66.709 & 71.606 & $19,8 \%$ & $17,6 \%$ & $7,3 \%$ & $51,2 \%$ \\
\hline Buenos Aires & Punta Alta & 56.108 & 56.165 & 57.296 & 58.315 & $0,1 \%$ & $2,0 \%$ & $1,8 \%$ & $3,9 \%$ \\
\hline Entre Ríos & Concepción del Uruguay & 46.247 & 55.942 & 64.954 & 72.528 & $21,0 \%$ & $16,1 \%$ & $11,7 \%$ & $56,8 \%$ \\
\hline Salta & $\begin{array}{l}\text { San Ramón de la Nueva Orán } \\
\text { (Est. Orán) }\end{array}$ & 32.910 & 50.717 & 66.915 & 76.070 & $54,1 \%$ & $31,9 \%$ & $13,7 \%$ & $131,1 \%$ \\
\hline Jujuy & San Pedro & 37.101 & 49.816 & 55.220 & 59.131 & $34,3 \%$ & $10,8 \%$ & $7,1 \%$ & $59,4 \%$ \\
\hline Buenos Aires & Chivilcoy & 44.579 & 49.142 & 52.938 & 58.152 & $10,2 \%$ & $7,7 \%$ & $9,8 \%$ & $30,4 \%$ \\
\hline Buenos Aires & Azul & 44.062 & 48.838 & 53.054 & 55.728 & $10,8 \%$ & $8,6 \%$ & $5,0 \%$ & $26,5 \%$ \\
\hline Buenos Aires & Mercedes & 41.484 & 45.895 & 51.967 & 56.116 & $10,6 \%$ & $13,2 \%$ & $8,0 \%$ & $35,3 \%$ \\
\hline
\end{tabular}




\begin{tabular}{|c|c|c|c|c|c|c|c|c|c|}
\hline Provincia & Aglomerado & Pobl. 1980 & $\mid$ Pobl. 1991| & Pobl. 2001 & Pobl. 2010 & $\begin{array}{l}\text { Var. \% } \\
1980- \\
1991 \\
\end{array}$ & \begin{tabular}{|l|} 
Var. \% \\
1991- \\
2001 \\
\end{tabular} & $\begin{array}{l}\text { Var. \% } \\
\text { 2001- } \\
2010\end{array}$ & $\begin{array}{l}\text { Var. \% } \\
1980- \\
2010 \\
\end{array}$ \\
\hline Chubut & Puerto Madryn & 20.478 & 44.895 & 57.614 & 81.315 & $119,2 \%$ & $28,3 \%$ & $41,1 \%$ & $297,1 \%$ \\
\hline Salta & Tartagal & 31.556 & 43.570 & 56.308 & 64.525 & $38,1 \%$ & $29,2 \%$ & $14,6 \%$ & $104,5 \%$ \\
\hline La Pampa & General Pico & 30.180 & 41.921 & 52.475 & 56.795 & $38,9 \%$ & $25,2 \%$ & $8,2 \%$ & $88,2 \%$ \\
\hline Córdoba & $\begin{array}{l}\text { Villa Carlos Paz - San Antonio de } \\
\text { Arredondo - Villa Río Icho Cruz }\end{array}$ & 29.6 & 42.912 & 61.165 & 69.840 & $44,7 \%$ & $42,5 \%$ & $14,2 \%$ & $135,5 \%$ \\
\hline Misiones & Oberá & 27.954 & 40.333 & 51.503 & 63.960 & $44,3 \%$ & $27,7 \%$ & $24,2 \%$ & $128,8 \%$ \\
\hline Formosa & Clorinda & 21.008 & 39.924 & 47.004 & 52.837 & $90,0 \%$ & $17,7 \%$ & $12,4 \%$ & $151,5 \%$ \\
\hline Tucumán & Concepción - Barrio San Roque & 29.355 & 38.102 & 46.561 & 50.375 & $29,8 \%$ & $22,2 \%$ & $8,2 \%$ & $71,6 \%$ \\
\hline $\begin{array}{l}\text { Tierra } \\
\text { Fuego }\end{array}$ & Río & 13.211 & 37.971 & 52.681 & 66.475 & $187,4 \%$ & $38,7 \%$ & $26,2 \%$ & $403,2 \%$ \\
\hline Misiones & Eldorado & 23.112 & 37.934 & 47.556 & 57.323 & $64,1 \%$ & $25,4 \%$ & $20,5 \%$ & $148,0 \%$ \\
\hline $\begin{array}{l}\text { Tierra del } \\
\text { Fuego }\end{array}$ & Ushuaia & 11.029 & 29.452 & 45.430 & 6.593 & $167,0 \%$ & $54,3 \%$ & $24,6 \%$ & $413,1 \%$ \\
\hline Santa Cruz & Caleta Olivia & 20.234 & 27.946 & 36.077 & 51.733 & $38,1 \%$ & $29,1 \%$ & $43,4 \%$ & $155,7 \%$ \\
\hline \multicolumn{2}{|c|}{ Totales de aglomerados intermedios } & 2.584 .316 & 3.407 .243 & 4.034 .709 & 4.606 .418 & $31,8 \%$ & $18,4 \%$ & $14,2 \%$ & $78,2 \%$ \\
\hline \multicolumn{2}{|l|}{ Totales país } & 27.949 .480 & 32.615 .528 & 36.260 .130 & 40.117 .096 & $16,7 \%$ & $11,2 \%$ & $10,6 \%$ & $43,5 \%$ \\
\hline \multicolumn{2}{|c|}{$\begin{array}{l}\text { Incidencia de aglomerados intermedios en total } \\
\text { país }\end{array}$} & 9 & 10 & 11 & 11,5 & & & & \\
\hline
\end{tabular}

Cuadro 2 - Dinámica demográfica de las ciudades intermedias

Fuente: Elaboración propia en base a Censo Nacional de Población, Hogares y Vivienda 1980-1991-2001-2010

\section{CIUDADES INTERMEDIAS CON DINÁMICAS DEMOGRÁFICAS DIFERENCIALES: PERGAMINO Y USUHAIA}

La selección de los dos casos de estudio se ha guiado en función del análisis realizado en el apartado anterior. Así, se han identificado dos aglomerados ${ }^{7}$ con marcadas diferencias en cuanto a su dinámica demográfica y sus localizaciones respecto a los principales centros de producción y consumo del país.

El primer caso corresponde a la ciudad intermedia de Pergamino, referida a un aglomerado compuesto por una única localidad censal y un único gobierno local, ubicada en la Provincia de Buenos Aires, próxima a los principales centros de producción y consumo del país y una de las menos dinámicas en términos demográficos. La otra ciudad intermedia seleccionada es Ushuaia, también referida a un aglomerado compuesto por una única localidad censal y un único gobierno local. Se ubica al Sur de la Patagonia Argentina en la Provincia de Tierra del Fuego, y es la ciudad intermedia más alejada de la Capital del País y la más dinámica entre los años 1980-2010.

\subsection{El caso de la ciudad intermedia de Pergamino en la Provincia de Buenos Aires}

La ciudad de Pergamino se ubica al Norte de la Provincia de Buenos Aires dentro de la llanura pampeana, a una distancia de $222 \mathrm{~km}$. de la Ciudad Autónoma de Buenos Aires y $110 \mathrm{~km}$. de la ciudad de Rosario en la vecina provincia de Santa Fe. Territorialmente, se estructura en la intersección de dos rutas nacionales: la Ruta Nacional 8 que conecta el Partido de Tigre -al Norte de la provincia de Buenos Aires- con la localidad de Villa Mercedes en la provincia de San Luis, atravesando el Sur de la provincia de Santa Fe y Córdoba, y la Ruta Nacional 188 que une la localidad de San Nicolás en la Provincia de Buenos Aires con General Alvear, localidad ubicada al Sur de la Provincia de Mendoza.

Históricamente en el período colonial, Pergamino formaba parte del Camino Real. En 1856, este alto del camino que dio origen a la ciudad, se constituyó en Municipio y cabecera del Partido homónimo, asumiendo la ciudad el rol funcional y administrativo tanto del espacio urbano como del rural. El modelo agroexportador

\footnotetext{
${ }^{7}$ Se toma la categoría de aglomerado como unidad observable para el trabajo sobre las ciudades intermedias, con particulares características geo-estadísticas definidas por el Instituto Nacional de Estadística y Censos de la República Argentina. Se entiende por aglomerado a una extensión urbana continua, compuesta por una o más localidades censales, por uno o más gobiernos locales, comprendida en una o más provincias. El aglomerado hace referencia a la ciudad real, a la mancha urbana que funciona en conjunto, independientemente de su pertenencia a una o más jurisdicciones.
} 
significó la llegada de migrantes y de los tendidos férreos de fines del siglo XIX. Pergamino desde sus orígenes asumió el carácter de centro regional, manteniendo un fuerte intercambio con otros centros regionales portuarios como Rosario y San Nicolás. Con la crisis de 1930 y el surgimiento del proceso de industrialización por sustitución de importaciones, disminuyó la demanda de mano de obra en el campo por la mecanización agrícola y la población migró a las grandes ciudades. Se frenó el crecimiento hasta los años 1960 y 1970 cuando se radicaron industrias textiles confeccionistas, metalúrgicas, plásticas y agro alimentarias, entre otras. Un nuevo freno se produjo a partir de 1976 con el proceso de apertura y desregulación de la economía que acompañó a la globalización y que llegó de la mano de la dictadura cívico-militar. Con ese proceso de desaceleró el crecimiento de la localidad. A partir de 1989, la privatización de los servicios públicos y la reforma del Estado también lo afectaron negativamente. Según el Plan Estratégico de Pergamino, el sector industrial y aún más el sector agropecuario, fueron los principales damnificados de este proceso

El perfil económico de Pergamino está centrado en la producción agropecuaria e industrial y se vio fuertemente perjudicado por la política neoliberal implementada en la década del 90 que incluyó el cierre de los ramales ferroviarios, la mecanización agrícola, la disminución de la actividad ganadera, el proceso de desregulación económica y apertura de los mercados. Como se menciona en el Plan Estratégico, estos aspectos negativos se combinaron con la "ausencia de políticas sectoriales de incentivo al desarrollo regional, con el consecuente debilitamiento de las localidades del Partido (...). Como consecuencia, la estructura radial actual es concentradora y polarizada en relación al centro hegemónico de Pergamino, provocando una fuerte relación e interdependencia de las localidades menores vinculadas por la red vial y ferroviaria -hoy prácticamente desactivada-." (Plan Estratégico de Pergamino: sin numeración).

Durante las últimas décadas del siglo XX varias industrias debilitadas por la apertura fueron desmanteladas, perdiéndose numerosos puestos de trabajo. A partir de los primeros años del siglo XXI se recuperó sensiblemente el empleo, se diversificó la industria y los servicios especializados vinculados a la actividad agro industrial. No obstante ello, o bien por el escaso tiempo transcurrido entre la recuperación de la localidad y el Censo 2010 no pudo visualizarse un correlato en transformaciones de la dinámica poblacional, o quizás ello sea porque la recuperación no significó la incorporación de mano de obra en forma masiva y atractora de población.

Según los datos del Censo del 2010, la ciudad de Pergamino contó con 91.399 habitantes. Al analizar su dinámica poblacional desde la década del 80' al 2010, se observa una tendencia al aumento de población, aunque siempre en proporciones algo menores al promedio nacional (Ver cuadro 2 y Gráfico 5). A su vez, la tendencia de crecimiento intercensal tiende a desacelerarse tanto a nivel nacional como del aglomerado. Así, la variación porcentual de población entre 1980 y 1991 fue del 14,0\%, cuando la variación del total país fue del 16,7\%. Para el período 91/2001, la variación porcentual de la ciudad fue del 9,3\% y la variación nacional fue del 11,2\% y en el último período (2001/2010), Pergamino obtuvo un crecimiento del 6,9\% y a nivel nacional fue del $10,6 \%$.

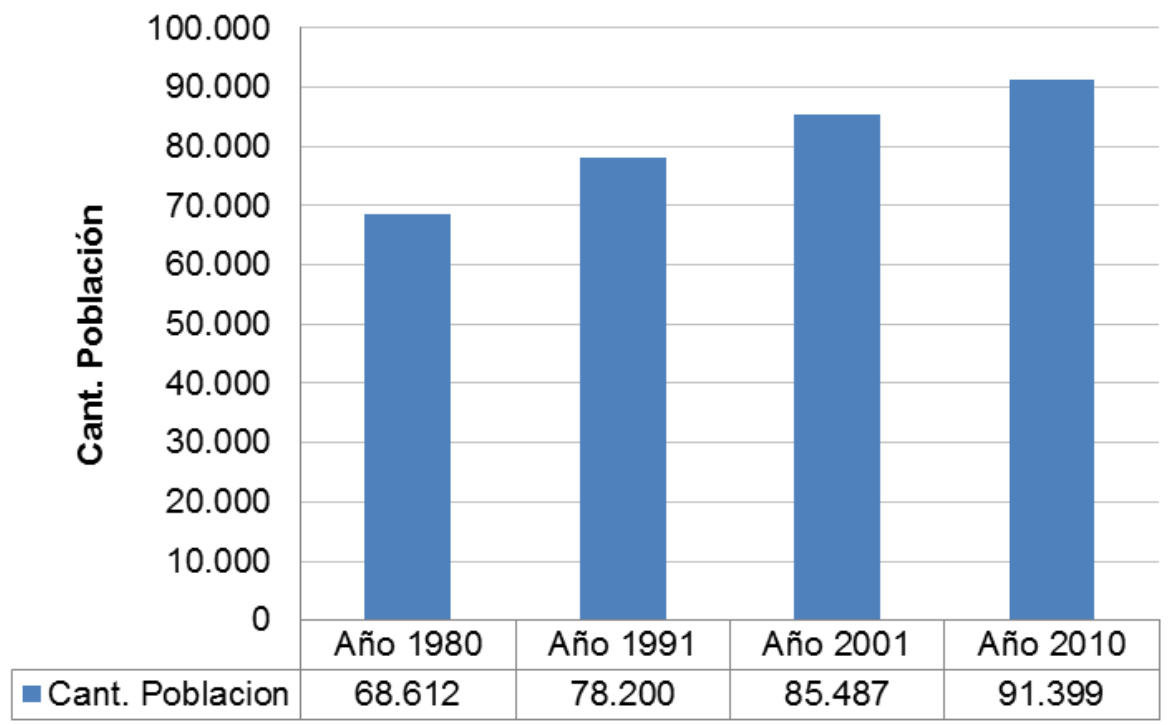

Gráfico 5: Variación intercensal de población en la ciudad de Pergamino. 1980-2010

Elaboración propia en base a Censo Nacional de Población, Hogares y Vivienda 1980-1991-2001-2010 
En cuanto al rol que tiene la ciudad en su entorno regional-urbano, Pergamino funciona como un centro de bienes y servicios relativamente especializados, al tiempo que se presenta como un centro de interacción social y cultural de una extensa área rural e industrial. Según los datos del Plan Estratégico de Pergamino, se estima que la influencia del nodo urbano se extiende en un radio aproximado de $50 \mathrm{~km}$., integrado por asentamientos urbanos y rurales. Asimismo, opera como centro articulador ligado a redes de infraestructura con conexiones a escala local, regional y nacional.

\subsection{El caso de la ciudad intermedia de Ushuaia en la Provincia de Tierra del Fuego}

Ushuaia, la ciudad más austral del mundo, es la Capital de la Provincia de Tierra del Fuego e Islas del Atlántico Sur. Está ubicada en la Bahía de Ushuaia rodeada al Oeste, Norte y Este por los Andes Fueguinos. Emplazada en extremo Sur del país, se encuentra a 2.277 km de Buenos Aires, $120 \mathrm{~km}$ (en línea recta) de Río Grande en la misma provincia, a 251 km de Punta Arenas en la Región de Magallanes, Chile.

Desde sus comienzos, Ushuaia fue el resultado de diversas corrientes migratorias, en donde la mayor actividad económica era la ganadería. Su economía estuvo ligada al sector público, en un principio asociada al Presidio (hoy explotado turísticamente) y luego con la instalación de la base de la Armada. Otras actividades eran la ganadería y la actividad hidrocarburífera, el sector secundario se reducía a unos pocos emprendimientos relacionados con la explotación maderera y la actividad turística era muy reducida, principalmente debido a las carencias de infraestructura.

Como menciona el Plan Estratégico de Ushuaia, la Ley 19.640/72 de promoción industrial, con un régimen especial fiscal y aduanero, fue decisiva en las últimas décadas del siglo XX y la primera década del corriente siglo (PET Ushuaia, 2003). Ushuaia fue destinataria de la primera Ley de Promoción Industrial que tuvo como objetivo impulsar el desarrollo del sector industrial en algunas provincias. El principal propósito de esta Ley fue ampliar la oferta de empleo, aunque también se destacan motivaciones geopolíticas del Gobierno Militar, que buscaba intensificar la población en contexto de conflicto limítrofe con Chile. Al comienzo las ventajas impositivas sólo fueron aprovechadas por un incipiente sector comercial, que importaba bienes de consumo e intentó desplegar el turismo, pero se vio limitado por la deficiencia de los transportes. Paradójicamente, a partir del golpe cívico militar de 1976 y la apertura comercial que incluyó en sus políticas, Tierra del Fuego se vio beneficiada con la radicación de industrias que llegaron a partir de 1980. La legislación hizo que la industria electrónica (especialmente, las fábricas de televisores, radios, grabadores y otros productos de audio) y de electrodomésticos (lavarropas, etc.), para subsistir, se instale en la ciudad de Ushuaia y se importen materias primas para transformarlas en productos terminados en Tierra del Fuego (Chocrón 2013).

Según Chocrón "la transición fue muy dura y costosa en términos de empleo y niveles de ingreso para la población local" (Chocron 2013:27). El autor señala que en 1986 se habían producido más de 100 radicaciones industriales en toda la Provincia, ocupando unas 3.000 personas en forma directa en la ciudad y unas 4.000 en forma indirecta. El Estado acompañó el fenómeno demográfico producido por el boom económico con el fomento para la radicación de médicos y maestros, y el conjunto de la actividad administrativa que cobró impulso en 1992 con la provincialización de Tierra del Fuego.

Los años 90 significaron, por un lado, la desregulación energética y el ingreso de regalías petroleras a la Provincia, y por otro, las dificultades del Régimen Promocional. La disminución de los beneficios de la Ley y la vigencia de las leyes del mercado, la incorporación de nuevas tecnologías y la automatización de los procesos, llevó a la disminución de la actividad: sólo 48 fábricas quedaron funcionando con 1.200 puestos directos y unos 2.000 indirectos en Ushuaia. El sector secundario, que en 1988 había aportado más del 66\% al PBG, redujo su participación hacia 1995 a un 33\%. La crisis significó un incremento del desempleo y una baja generalizada de salarios, que acompañó la retracción general de la economía provincial, afectando al resto de las actividades. Toda esta situación impactó en el sector público, que creció para paliar las crecientes demandas sociales.

Siguiendo los datos del mismo autor, las industrias tuvieron que disminuir sus dotaciones de personal, pero pudieron colocar sus productos en el mercado nacional a precios competitivos con los artículos importados, en años en los que se amplió el consumo interno (en los primero años del siglo), lo que motorizó la industria y posibilitó la recuperación de la actividad. Actualmente, ese modelo está nuevamente en crisis.

Por su parte, hubo una gran inversión pública y privada desde los últimos años de siglo pasado. Se construyó el Aeropuerto Internacional, se amplió el muelle del Puerto, se pavimentó la RN3, se construyeron nuevos 
hoteles de 4 y 5 estrellas, entre otras obras. Esto se vio acompañado por el incremento en el número de turistas, que incluye, desde la ampliación del muelle, tráfico turístico antártico.

Los datos poblacionales dan cuenta de los procesos mencionados. El crecimiento que experimentó la ciudad entre 1980 y 2010 fue en términos relativos de 413\%, multiplicando en más de cuatro veces su población de 1980 en tres décadas, y superando ampliamente en porcentaje al conjunto del país, que en el mismo periodo creció en 43,5\%. El mayor crecimiento se verificó entre 1980 y 1991, cuando alcanzó el 167\%, mientras que entre 1991 y 2010 el crecimiento fue del 54,35, y entre 2001 y 2010 de 24,6\%. Como se ve, si bien en términos relativos el crecimiento fue disminuyendo notoriamente, siguió siendo muy superior al experimentado por el conjunto del país. En 2010 Ushuaia reunió 56.593 habitantes.

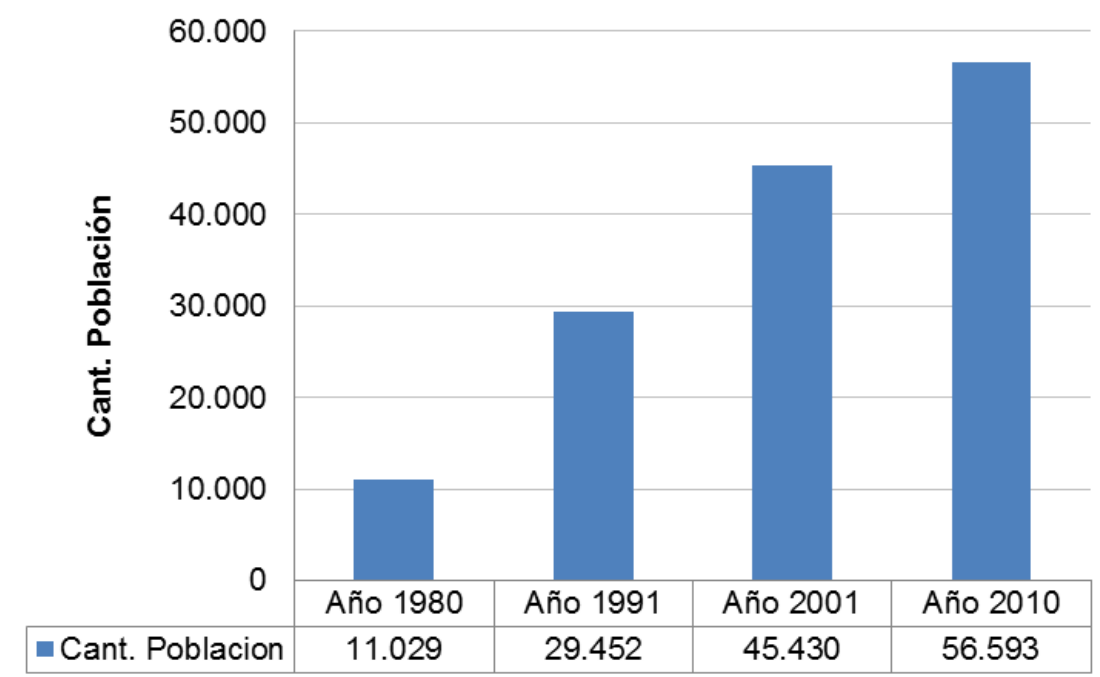

Gráfico 6: Variación intercensal de población en la ciudad intermedia de Ushuaia 1980-2010

Fuente: Elaboración propia en base a Censo Nacional de Población, Hogares y Vivienda 1980-1991-2001-2010

El rol de Ushuaia está signado en los últimos años por un peso significativo de la industria manufacturera (en crisis actual) y de servicios vinculados a la actividad turística. De todas formas la dependencia de los recursos nacionales que llegan a través de la coparticipación federal de impuestos es muy importante. Según los Informes Productivos Provinciales del Ministerio de Hacienda, en el 2016, el Estado Nacional le aportó a la provincia el 46\% de sus ingresos (Ministerio de Hacienda, 2017).

\section{CONSIDERACIONES FINALES}

Este trabajo se propuso avanzar en el debate acerca de la caracterización de las ciudades intermedias y su rol en el sistema regional que integran. Para ello, se consideraron dos casos de estudio que presentaron históricamente un desarrollo opuesto.

Por un lado, la ciudad intermedia de Pergamino, ubicada en el corazón de la llanura pampeana, una región caracterizada por la fertilidad de su tierra y un clima favorable tanto para el desarrollo de las actividades agropecuarias y ganaderas, como para el asentamiento de población. Dadas estas condiciones y su cercanía a grandes núcleos urbanos como Rosario y la Ciudad de Buenos Aires, se han desarrollado tempranamente buenas conexiones viales y férreas para conectar el nodo urbano con las áreas de más dinámicas de Santa Fe y Buenos Aires, así como se impulsó un rol central entre las pequeñas localidades circundantes. Sin embargo, Pergamino no contó con el apoyo de políticas públicas que mitigaran los efectos de la implementación de los modelos económicos que la perjudicaron, obstaculizando el desarrollo de sus actividades económicas centrales, las actividades agrarias y la industria. En este sentido, también es posible que su cercanía a grandes núcleos urbanos, haya permitido que, en tiempos de crisis, Rosario o el GBA hayan ejercido un efecto gravitacional mayor, reteniendo población y permitiendo que algunos servicios especializados se comanden desde allí, en lugar de radicarse localmente en Pergamino.

Contrariamente, la ciudad intermedia de Ushuaia está ubicada en el extremo Sur del país, en un área de gran belleza natural por su cercanía a los alpes fueguinos, pero con un clima muy adverso para la radicación de población, dada sus bajas temperaturas. Por este motivo, Ushuaia fue poblada siguiendo la voluntad de ejercicio de soberanía del Estado. Si bien Ushuaia contaba ya con población originaria, tuvo a lo largo de la 
historia, varias oleadas migratorias impulsadas por diversas estrategias y medidas impulsadas por el Estado Nacional. Eso explica su exponencial crecimiento demográfico. Fue el Estado el garante principal de las condiciones económicas e institucionales necesarias para el desarrollo regional, y sigue siendo el Estado el que, por medio de infraestructura, organiza el territorio para el impulso de actividades. El desarrollo de la ciudad (y el de la Provincia) en general estuvo vinculado a decisiones externas a su territorio.

En relación a las dinámicas demográficas del sistema regional-urbano argentino, y en particular de las ciudades intermedias, se ha observado que el crecimiento relativo del conjunto de las mismas fue superior a los promedios nacionales desde 1980 hasta 2010, incluso al crecimiento del Gran Buenos Aires. Asimismo, se ha visto que ha aumentado la incidencia de las ciudades intermedias en la distribución territorial de la población argentina en cada período intercensal comprendido entre 1980 y 2010. Si bien el sentido de las variaciones relativas que se mencionan no tienen un correlato con las variaciones absolutas (debido a la primacía urbana en Argentina), este proceso podría representar una tendencia hacia la desconcentración urbana.

Por otro lado, un elemento que podría arrojar luz a la identificación de relaciones causales de las diferenciales dinámicas demográficas de las ciudades intermedias argentinas entre los años 1980 y 2010, es el crecimiento relativo que se ha visto a favor de aquellas más distantes de los principales centros de producción y consumo, en contraposición a las dinámicas demográficas más estancadas que presentaron las más próximas a los principales centros urbanos del país.

Si entendemos que no se puede pensar la dinámica territorial en forma autónoma de los modelos de desarrollo y de las estructuras sociales y económicas, los alcances de las transformaciones de las dinámicas urbanasregionales y de las ciudades intermedias hacia un desarrollo más equilibrado, están limitadas por la concentración económica y social y por las políticas públicas que se asuman dentro de ese entramado. Lo espacial, lo social y lo económico no pueden ser pensados en forma independiente.

\section{BIBLIOGRAFÍA}

Bellet SANFeliu, C. y Llop J. M. (2004). Miradas a otros espacios urbanos: las ciudades intermedias. Geo Crítica/Scripta Nova. Revista electrónica de geografía y ciencias sociales, 8 (165). Pp. 1-26.

BOLAY, J. C. Y RABINOVICH, A. (2004). Ciudades intermedias: ¿una nueva oportunidad para un desarrollo regional coherente en América Latina? Cities, 21 (5). Pp. 00-00.

BENKO G Y LIPIETZ A. (1994). El nuevo debate regional", En BENKO y LIPIETZ (Eds) Las regiones que ganan, Edicones Alfons el Magnànim, València.

CASTells, M. (1999). La Era de la Información. Vol. I. La Sociedad Red. Madrid: Alianza Editorial, Pp. 409462.

De MatTos Carlos A (1984). Ciudades intermedias y desconcentración territorial: propósitos, alcances y viabilidad. Revista EURE, Vol. 11, núm. 32. Pp. 7-34

ERBITI, C. (2007). Transformaciones del sistema urbano argentino a fines del Siglo XX: Desafíos para la gestión del territorio. IV Seminario Ordenamiento Territorial, Ordenamiento territorial y Problemáticas urbanas, Mendoza, 7-9 de Noviembre.

Hardoy, J.E. - SatTerthwalte, D. (1987). La ciudad legal y la ciudad ilegal Editorial: Gel, Grupo Editor Latinoamericano, Colección Estudios Políticos y Sociales, Buenos Aires

Hildreth, P. A. (2006). Roles and Economic Potential of English Medium-Sized Cities: A discussion paper. Manchester: University of Salford press.

HARVEY, D. (1977). Urbanismo y desigualdad. Traducción de Marina González Arenas. Primera edición. Madrid: Siglo XXI editores.

ISARD, W. (1956). Location and space economy. Cambridge: The MIT press. 
LINDENBOIM, J. \& KENNEDY, D. (2004). Dinámica urbana argentina. 1960-2001. Reconstrucción y análisis de la información necesaria. Documentos de Trabajo $N^{\circ} 3$, Buenos Aires, CEPED- IIE - FCE - UBA

LLOP TORNÉ, J. M. (1999) Ciudades intermedias y urbanización mundial. Ajuntament de Lleida, UNESCO, UIA, Ministerio de Asuntos Exteriores.

Méndez, R., Melero, A., Calatrava, A. (2008). Desarrollo territorial policéntrico y ciudades intermedias: recursos productivos y dinámicas económicas locales en Andalucía. En Estudios Geográficos, LXIX, 265, pp. 637-663, julio-diciembre 2008

MICHELINI, J. J. \& DAVIES, C. (2009). Ciudades intermedias y desarrollo territorial: un análisis exploratorio del caso argentino. Documentos de Trabajo GEDEUR - 5

MontoyA, J. W. (2004). Sistemas urbanos en América Latina: globalización y urbanización. Cuadernos de Geografía, 13 (0). Pp. 39-58.

NovoA TORRES, E. A. (2016). Geografías de la diferencia. Espacialidad, política y acción social. Bogotá: Universidad Nacional de Colombia.

SANTOS. M. (1996). Metamorfosis del espacio habitado. Barcelona: Oikos-tau.

SASSONE, S. M. (2000). Reestructuración territorial y ciudades intermedias en la Argentina. Ciudad y Territorio: Estudios Territoriales, 32 (123). Pp. 57-92.

VAPÑARSky, C. \& GoROJOVSky, N. (1990). El crecimiento urbano en la Argentina. Buenos Aires: Grupo Editor Latinoamericano.

VAPÑARSKY, C. (1994). El concepto de localidad: definición, estudios de caso y fundamentos teóricometodológicos. Censo Nacional de Población y Vivienda 1991. INDEC (Serie D, Número 4), Buenos Aires: Ministerio de Economía.

\section{Fuentes electrónicas:}

CAPEL, H. (2003). Una mirada histórica sobre los estudios de redes de ciudades y sistemas urbanos. GeoTrópico, 1 (1), 30-65, versión PDF. Online. (Fecha de consulta: 1/03/2018)

http://www.geotropico.org/1 1 Capel.html

CHOCRÓN, G. (2013). Análisis del régimen nacional de promoción industrial de tierra del fuego entre 1980 y el 2010 desde el paradigma del desarrollo interno propio. Tesis se graduación. Facultad: Ciencias Económicas. Universidad Fasta. (Fecha de consulta: 1/03/2018)

http://redi.ufasta.edu.ar:8080/xmlui/bitstream/handle/123456789/389/2013 CP 006.pdf?sequence=1

Instituto Nacional de Estadísticas y Censos (INDEC). Censo Nacional de Población, Hogares y Viviendas de 1980, 1991, 2001, 2010. Recuperados de:

http://www.indec.gob.ar/nivel3 default.asp?id tema 1=2\&id tema $2=41$

Ministerio de Hacienda (2017) Tierra del Fuego. Informes Productivos Provinciales. Año 2. №17. (Fecha de consulta: $1 / 03 / 2018$ )

https://www.economia.gob.ar/peconomica/dnper/fichas provinciales/Tierra del Fuego.pdf

Plan Estratégico de Pergamino (Fecha de consulta: 1/03/2018)

https://www.mininterior.gov.ar/planificacion/pdf/planes-loc/BUENOSAIRES/Plan-Estrategico-Pergamino.pdf

Plan Estratégico de Ushuaia (2013). (Fecha de consulta: 1/03/2018)

https://www.mininterior.gov.ar/planificacion/pdf/planes-loc/TIERRADELFUEGO/Plan-Estrategico-Ushuaia2003-2013.pdf 